\title{
Extracellular Matrix in Aging Aorta
}

\author{
Akiko Mammoto $^{1,2 *}$, Kienna Matus ${ }^{1}$ and Tadanori Mammoto ${ }^{1,3 *}$ \\ ${ }^{1}$ Department of Pediatrics, Milwaukee, WI, United States, ${ }^{2}$ Department of Cell Biology, Neurobiology and Anatomy, Milwaukee, \\ WI, United States, ${ }^{3}$ Department of Pharmacology and Toxicology, Medical College of Wisconsin, Milwaukee, WI, United States
}

OPEN ACCESS

Edited by:

Hiromi Yanagisawa,

University of Tsukuba, Japan

Reviewed by:

Yoshito Yamashiro,

University of Tsukuba, Japan

Elena MacFarlane,

Johns Hopkins Medicine,

United States

*Correspondence:

Akiko Mammoto

amammoto@mcw.edu

Tadanori Mammoto

tmammoto@mcw.edu

Specialty section:

This article was submitted to

Cell Adhesion and Migration,

a section of the journal

Frontiers in Cell and Developmental

Biology

Received: 25 November 2021

Accepted: 07 February 2022

Published: 21 February 2022

Citation:

Mammoto A, Matus $K$ and Mammoto T (2022) Extracellular Matrix in Aging Aorta.

Front. Cell Dev. Biol. 10:822561. doi: 10.3389/fcell.2022.822561
The aging population is booming all over the world and arterial aging causes various ageassociated pathologies such as cardiovascular diseases (CVDs). The aorta is the largest elastic artery, and transforms pulsatile flow generated by the left ventricle into steady flow to maintain circulation in distal tissues and organs. Age-associated structural and functional changes in the aortic wall such as dilation, tortuousness, stiffening and losing elasticity hamper stable peripheral circulation, lead to tissue and organ dysfunctions in aged people. The extracellular matrix (ECM) is a three-dimensional network of macromolecules produced by resident cells. The composition and organization of key ECM components determine the structure-function relationships of the aorta and therefore maintaining their homeostasis is critical for a healthy performance. Age-associated remodeling of the ECM structural components, including fragmentation of elastic fibers and excessive deposition and crosslinking of collagens, is a hallmark of aging and leads to functional stiffening of the aorta. In this mini review, we discuss ageassociated alterations of the ECM in the aortic wall and shed light on how understanding the mechanisms of aortic aging can lead to the development of efficient strategy for aortic pathologies and CVDs.

Keywords: extracellular matrix, aging, aorta, stiffness, elastin, collagen

\section{INTRODUCTION}

The aging population is booming worldwide. At present, those aged over 65 years old constitute $16.5 \%$ of the population in the United States (US), and this number is expected to rise to $22 \%$ by 2050 (https://www.census.gov/content/dam/Census/library/publications/2020/demo/p25-1146.pdf).

Aging is associated with structural and functional alterations in tissues and organs that over time, lead to various age-associated pathologies (Donato et al., 2018; Franceschi et al., 2018). The arteries transport circulating cells, oxygen and nutrients to local tissues and organs. The structure and function of the arteries are significantly altered during aging, which makes aging a major risk factor for cardiovascular diseases (CVDs) (Heidenreich et al., 2011; North and Sinclair, 2012; Paneni et al., 2017). Arterial aging is characterized by increased stiffness, reduced elasticity, impaired distensibility, endothelial dysfunction, and deregulated vascular tone (Paneni et al., 2015; Sun, 2015). To develop more efficient treatment to slow down arterial aging and prevent age-associated pathologies, it is necessary to comprehensively understand the structural and functional alterations in the aging arteries.

The extracellular matrix (ECM) is a three-dimensional network of macromolecules that determines morphological and physical properties of the tissues and organs (Frantz et al., 2010; Theocharis et al., 2016). Homeostasis of the ECM network is critical for maintaining tissue structurefunctional relationships, and aberrant ECM remodeling contributes to various pathological conditions in the aging population (Birch, 2018; Theocharis et al., 2019). ECM proteins such as elastin, collagens, and soluble proteoglycans are the major components of the arterial wall (Jana et al., 


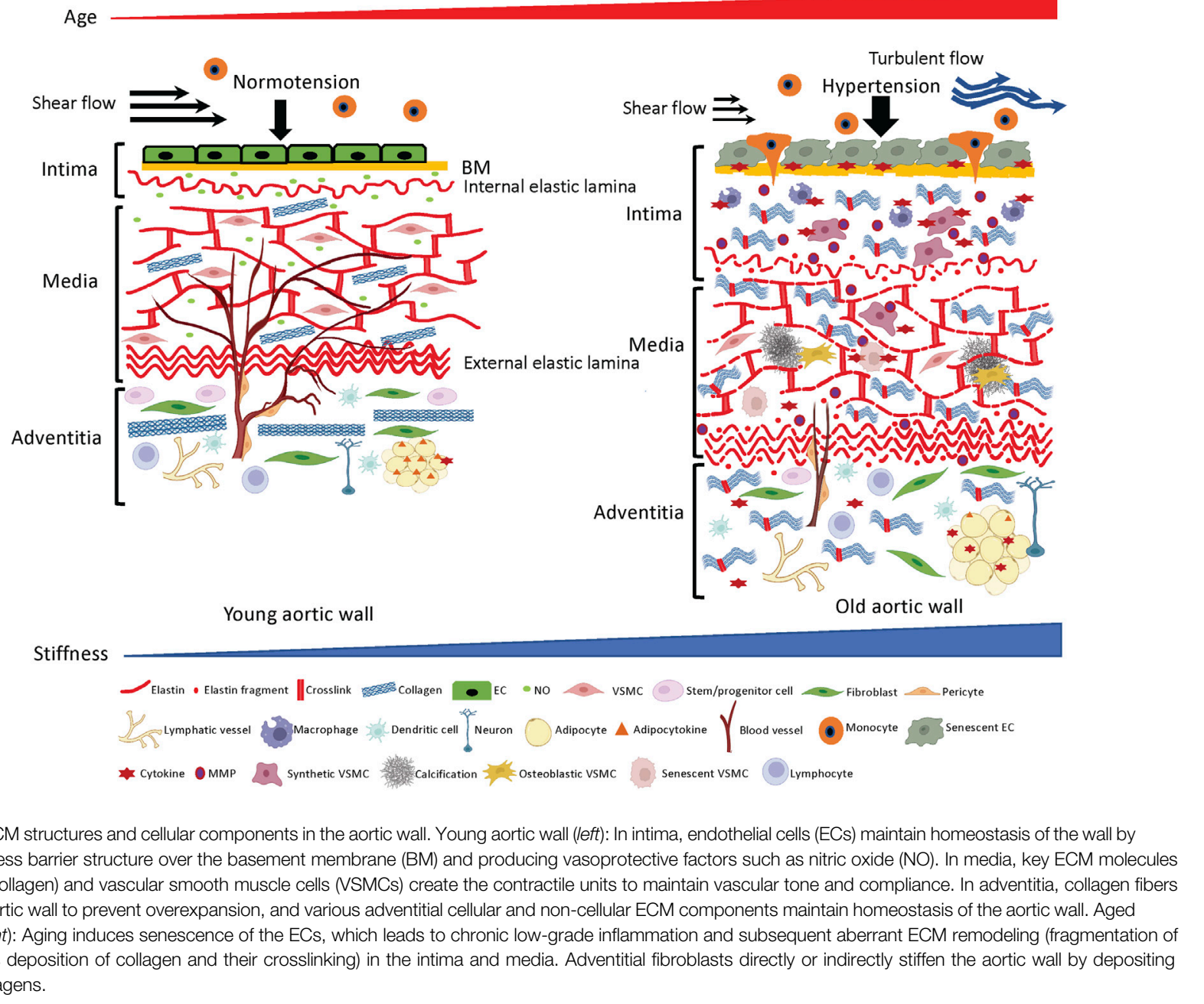

2019). In large arteries, the ECM provides a structural framework, which not only withstands a wide range of tensile stresses, but also preserves its shape and functionality (Wagenseil and Mecham, 2009; Beenakker et al., 2012). In addition to structure, the ECM provides signaling cues that regulate proliferation and differentiation of resident cells [vascular smooth muscle cells (VSMCs), endothelial cells (ECs)] in the arterial wall (Davis and Senger, 2008; Nakayama et al., 2014).

The aorta is the largest elastic artery and the ascending region is anatomically positioned at the top of the left ventricle, which then arches (aortic arch) and branches into smaller arteries (right and left carotid and subclavian), before descending into the abdominal area. Elasticity of the aorta facilitates distension and recoil of the aortic wall during cardiac cycles to transform pulsatile flow generated by the left ventricle into steady flow to maintain local circulation in tissues and organs (Belz, 1995; Westerhof et al., 2009). The ECM composition and its three-dimensional structure determine morphology, mechanical property and functionality of the aorta (Wagenseil and Mecham, 2009). For example, elastic fibers and associated microfibrils and proteoglycans in the media (Halper and Kjaer, 2014; Hedtke et al., 2019; Halabi and Kozel, 2020) allow the aorta to expand and recoil during cardiac cycles (Cocciolone et al., 2018). On the other hand, fibrillar collagens (predominantly collagen I and III) in the media and adventitia are responsible for the tensile strength of the aortic wall to withstand the axial pressure created by the beating left ventricle (Wagenseil and Mecham, 2009). Along aging, elastic fibers in the aortic wall are progressively fragmented and lose their original elastic properties due to the life-long mechanical loads and lowgrade chronic inflammation (Antonicelli et al., 2007; Duca et al., 2016; Heinz, 2021). Morphologically, the aortic aging is characterized by dilation, tortuousness and wall thickening in the intima and media layers (Gariepy et al., 1998; Lakatta and Levy, 2003), predominantly resulting from structural remodeling of the ECM and deregulated behaviors of VSMCs (Collins et al., 2014b). Fragmentation of the elastic fibers, aberrant collagen deposition and excess crosslinking of these ECM molecules lead to loss of elasticity and stiffening of the aortic wall (Qiu et al., 2007; Kohn et al., 2015; Duca et al., 2016). Aortic stiffness is known to parallel aortic aging and has 

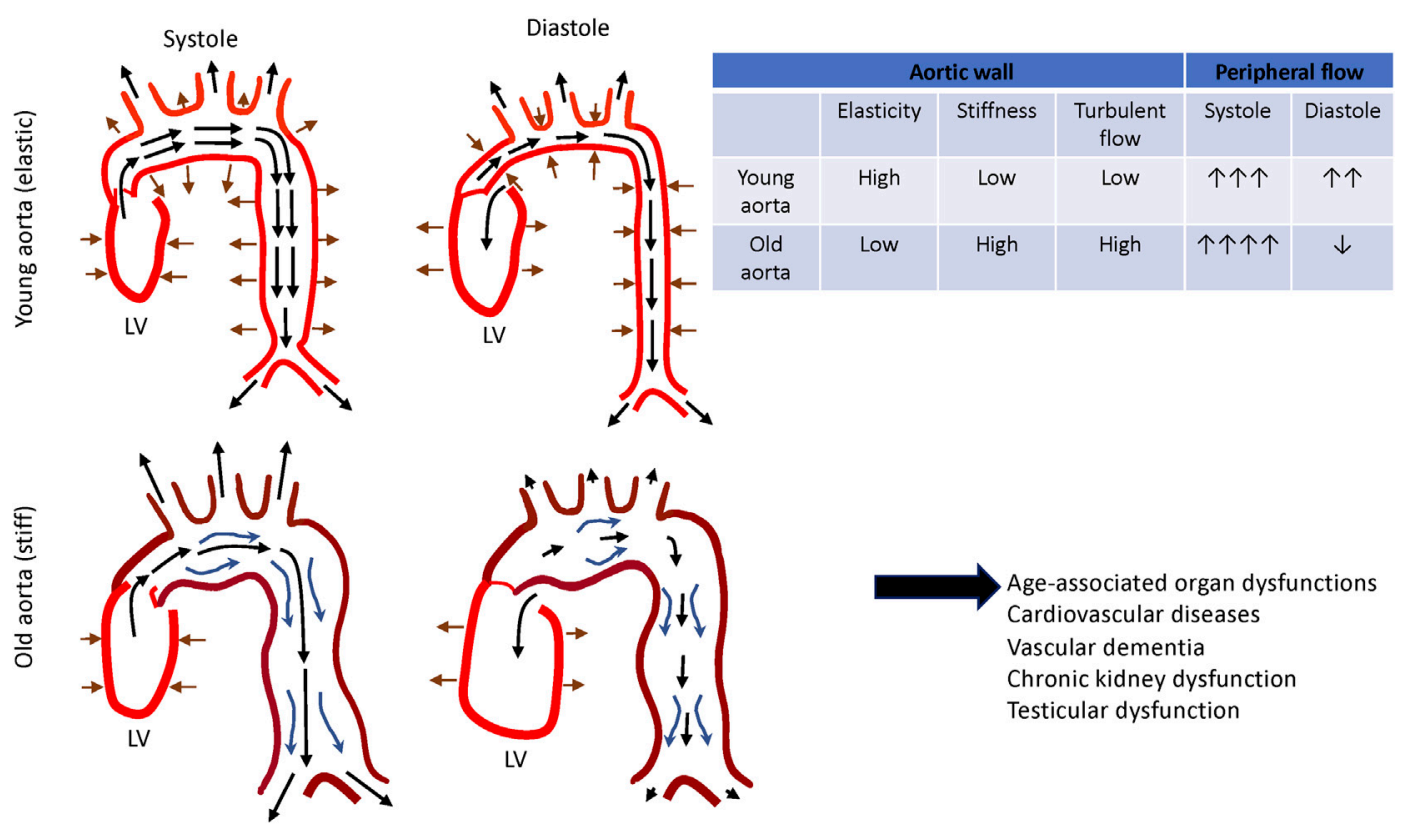

FIGURE 2 | Changes in aortic functions during aging. Aortic wall stores energy generated by the left ventricle during systole and release the energy during diastole by returning to its initial dimension. This facilitates smooth and constant circulation in the peripheral tissues and organs (top). Aged aorta becomes dilated and tortuous. Together with these morphological changes, thickening and stiffening of the aging aortic wall disturb the local circulation, which leads to the tissue and organ dysfunction (bottom).

been regarded as an independent predictor of morbidity and mortality of CVDs in the aging population (Mceniery et al., 2007; Wallace et al., 2007; Mitchell et al., 2010); aortic stiffening precedes clinical hypertension and is considered as the earliest predictor of hypertension (Liao et al., 1999; Dernellis and Panaretou, 2005; Peralta et al., 2010; Sun, 2015). In this mini review, we discuss the role of aberrant ECM remodeling in aging aorta and the underlying mechanism.

\section{ANATOMY OF AORTA}

\section{Intima}

The intima is the innermost layer of the aortic wall composed of a single layer of ECs, basement membrane (BM) and subendothelial space (Figure 1, left panel). ECs form a seamless monolayer over the BM, a thin pliable ECM membrane mainly consisting of laminin, collagen IV, fibronectin, perlecan, and heparan sulfate proteoglycans (Hallmann et al., 2005; Yurchenco, 2011). The BM plays crucial roles in the signaling events that regulate migration, proliferation, survival and barrier functions of resident vascular ECs (Davis and Senger, 2005). The vascular endothelium regulates homeostasis of the vessel by producing various vasoprotective factors such as nitric oxide (NO) to maintain vascular tone and blood flow (Sandoo et al., 2010; Kruger-Genge et al., 2019). The single layer of internal elastic lamina not only physically supports ECs and the BM, but also acts as a barrier structure between intima and media to prevent infiltration of circulating factors and media-derived cells that may trigger pathogenesis.

\section{Media}

The media layer of the vessel is predominantly composed of the lamellar units of elastic fibers, collagen fibers and VSMCs (Clark and Glagov, 1985; Tsamis et al., 2013) (Figure 1, left panel) and determines the elastic properties of the aortic wall (Taghizadeh et al., 2015). Elastic fibers and VSMCs create a highly organized media layer within the vessel wall. VSMCs synthesize tropoelastin, which is a water-soluble precursor to elastin (Ozsvar et al., 2021). Tropoelastin monomers generated by VSMCs undergo extensive cross-linking to create mature elastin (Sandberg et al., 1981; Krettek et al., 2003), which is assembled into elastic fibers to form the elastin-contractile units around the VSMCs in the media. VSMCs are heterogenous and exhibit a high degree of plasticity (Alexander and Owens, 2012). In the media layer, VSMCs are the most abundant cell type and play key roles in maintaining structure and functions of the aorta (Lacolley et al., 2017). Upon circumferential stretching, the elastic fibers within the aortic wall store the energy created from the pumping left ventricle during systole and release the energy during diastole by returning to their initial dimension (Figure 2, upper panel). This is indispensable for maintaining a regular and efficient circulation in the peripheral tissues and organs during the cardiac cycle (Belz, 1995). Collagens closely associate with elastic fibers in the media (Dingemans et al., 2000) and contribute to aortic wall stiffness and strength (Wagenseil and Mecham, 2009; Wang et al., 2021). Collagen types I and III are enriched within the aortic wall; type I collagen localizes around the VSMCs, while type III collagen exists alongside the multiple layers of external elastic 
lamella in the media layer (Shekhonin et al., 1987). These series of cellular and ECM structural units in the media are the major determinants of the elastic properties of the aortic wall.

\section{Adventitia}

The outermost layer of the aortic wall is the adventitia, composed of stem/progenitor cells, fibroblasts, pericytes, vasa vasorum (VV), lymphatic vessels, inflammatory cells (e.g., macrophages, dendritic cells, mast cells, $\mathrm{T}$ cells, and $\mathrm{B}$ cells), perivascular neurons, and adipocytes that are distributed in the collagenrich connective tissue (Figure 1, left panel). ECM structures in the adventitia determine physical strengths of the aortic wall (Beenakker et al., 2012; Stenmark et al., 2013), which bears over half of the mechanical load to protect the aortic wall from overdistension. Importantly, adventitia is a regulatory center for vascular injury, and a pathological adventitia structure contributes to age-related vascular disease (Majesky et al., 2012; Stenmark et al., 2013; Tinajero and Gotlieb, 2020). Several types of stem/progenitor cells that reside adjacent to the media have the capacity to differentiate into VSMCs, ECs, chondrocytes, adipocytes, macrophages and myofibroblasts to maintain homeostasis of the aortic wall in response to physiological and pathological stimuli (Majesky et al., 2011; Majesky et al., 2012; Jolly et al., 2021). Fibroblasts that are absent in the intima and media are dispersed within the adventitia, where they serve to deposit collagen fibrils (Ross and Glomset, 1973; Kohn et al., 2015). VV is a specialized microvasculature that transports nutrients and oxygen to the adventitia and two-thirds of the media layer within the aortic wall. Adventitial lymphatic vessels modulate inflammation of the aortic wall by draining interstitial fluid and trafficking the immune cells through the aortic wall (Kutkut et al., 2015; Yeo et al., 2021). Perivascular innervation in the adventitia modulates functions of VSMCs and ECs to regulate vascular tone (Nava and Llorens, 2019). Perivascular adipose tissue (PVAT) also plays important roles in homeostasis of the aortic wall by releasing adipocytokines, chemokines and growth factors to determine inflammation status and stiffness of the aortic wall (Ozen et al., 2015; Nava and Llorens, 2019).

\section{DISCUSSION}

\section{Aging of Intima and Media}

With aging, anti-aging factors (e.g., GDF11, IGF-1, klotho, oxytocin, nitric oxide (NO)) decrease, while pro-aging factors (e.g., $\beta 2$-microglobulin, oxidized low-density lipoproteins) increase in the circulating blood (Ozen et al., 2015; Smith et al., 2015; Cannata et al., 2017; Yang et al., 2017; Sahu et al., 2018; Kang and Yang, 2020; Kiss et al., 2020; Rybtsova et al., 2020). ECs that cover the surface of blood vessels orchestrate arterial homeostasis by mediating vascular tone, coagulation, immune response, inflammation, metabolism and angiogenesis (Michiels, 2003; Busse and Fleming, 2006; Pober et al., 2009; Falkenberg et al., 2019; Kruger-Genge et al., 2019), and are constantly exposed to pro- and anti-aging factors in the blood. In concert with age-associated hemodynamic challenges (e.g., hypertension, decreased shear flow and increased turbulent flow resulting from dilated and tortuous aged aorta) (Lantz et al., 2015; Buford, 2016; Ha et al., 2018) and intrinsic cellular aging programs (Hohensinner et al., 2016; Morgan et al., 2018), degenerative imbalances in anti- and pro-aging factors directly or indirectly accelerate endothelial senescence in the aortic wall (Erusalimsky and Kurz, 2006). Senescent ECs mitotically halt and become dysfunctional (Donato et al., 2015; Bhayadia et al., 2016) (Figure 1 right panel), while exhibiting pro-inflammatory phenotypes (Wang et al., 2014a; Wang et al., 2014b; Pantsulaia et al., 2016) such as attenuated endothelial NO production, increased endothelin-1 (ET-1) release, production of inflammatory cytokines [e.g., IL-1, IL-6, IL-8, TNF- $\alpha$, monocyte chemoattractant protein-1 (MCP-1)] (Maier et al., 1990; Pantsulaia et al., 2016), activation of surface adhesion receptors (e.g., ICAM-1, VCAM-1) and disruption of barrier function (Krouwer et al., 2012). Consequently, circulating immune cells are activated and adhere to the surface of dysfunctional ECs, which promotes their infiltration through the endothelium and into the subendothelial space (Trott et al., 2018) (Figure 1, right panel). Activated macrophages also release pro-inflammatory cytokines such as TNF- $\alpha$, IL-1b, IL-6 and INF- $\gamma$ (Wang et al., 2007; Lesniewski et al., 2011a; Lesniewski et al., 2011b) and chronic, low-grade sterile inflammation ensues in the aortic wall (Wang et al., 2014a; Wang et al., 2014b; Duca et al., 2016) (Figure 1, right panel). In response to the age-associated proinflammatory microenvironment, degenerative ECM remodeling (e.g., degradation of BM, fragmentation of internal elastic laminae, excessive deposition and crosslinking of collagens) (Bruel and Oxlund, 1996; Tsamis et al., 2013; Steppan et al., 2019) leads to thickening and stiffening of the ECM network within the subendothelial space (Guyton et al., 1983; Lakatta and Levy, 2003) (Figure 1, right panel). As a result, ECs sense the substrate stiffness (Collins et al., 2014a), which in turn, further aggravates endothelial dysfunction (Fels et al., 2012). For example, stiffening of the subendothelial space due to aberrant ECM remodeling sensitizes ECs to oxidative stress, accelerates EC senescence (Urbano et al., 2019), and disrupts EC barrier function to further promote infiltration of activated immune cells (Huynh et al., 2011). Aberrant cell-ECM interactions also reduce NO bioavailability and impair endothelial-dependent vasodilation (Paar et al., 2014). Decreased NO bioavailability also stimulates activation of MMPs (Nascimento et al., 2019), which further degrades the matrix composition of the aortic wall, particularly within collagen and elastic fibers (Tronc et al., 2000; Upchurch et al., 2001; Zaragoza et al., 2002).

These changes in the intima layer contribute to aortic aging and pathogenesis of CVDs (inside-out theory: inner layer triggers remodeling of aortic wall) (Donato et al., 2015; Yin and Pickering, 2016). Physiological crosstalk between ECs, immune cells, ECM and VSMCs maintains homeostasis of the healthy aorta, while age-associated changes lead to deregulated crosstalk and aberrant aortic wall remodeling (Mendez-Barbero et al., 2021). Aged ECs and disorganized underlying ECM structures also synergistically stimulate migration of medial VSMCs into the intima ( $\mathrm{Li}$ et al., 1999; Miller et al., 2007). These VSMCs aberrantly remodel native 
ECM structures in the intima (Schwartz et al., 1995) (Figure 1, right panel). Decreased expression of contractile proteins (Bochaton-Piallat et al., 1993; Bochaton-Piallat et al., 2001; Moon et al., 2003; Ferlosio et al., 2012) and increased expression of pro-inflammatory and migratory factors such as MMPs (Moon et al., 2003), MCP-1 (Spinetti et al., 2004) and PDGFR (Wang et al., 2012) in the VSMCs contribute to the intimal remodeling in the aging aorta (Li et al., 1999). These synthetic VSMCs further degrade elastic fibers, while deposit and crosslink collagens that are 100-1000 times stiffer than elastin between the fragmented elastic fibers in intima and media (Hays et al., 2018) (Figure 1, right panel). In the aging aorta, deregulated collagen deposition and crosslinking lead to fibrosis and thickening of the aortic wall (Movat et al., 1958; Spina and Garbin, 1976; Mccullagh et al., 1980; Toda et al., 1980; Andreotti et al., 1985; Shekhonin et al., 1987; Wang et al., 2006; Lyck Hansen et al., 2015). Aged ECs generate excess reactive oxygen species (ROS) through mitochondrial respiratory chain, NADPH oxidases and down regulation of antioxidant enzymes (Donato et al., 2015) to create chronic oxidative stress and subsequent low-grade inflammatory phenotype in the aortic wall (Ungvari et al., 2008), which leads to severe aortic pathologies such as atherosclerosis and abdominal aneurysm (AAA) (Ungvari et al., 2010; Peshkova et al., 2016; Golledge, 2019) in aged people. AAA is a 15th-leading cause of overall death in the United States and is an age-associated CVD (prevalence of men over 65 years is $4-8$ percent) (Sakalihasan et al., 2018). The prevalence of aortic atherosclerosis also significantly increases along aging (Jaffer et al., 2002; Oyama et al., 2008; Chen et al., 2013) and causes serious CVDs such as coronary artery disease and stroke (Kronzon and Tunick, 2006; Di Tullio et al., 2008).

The heart beats over 100,000 times a day and each cardiac cycle induces pulsatile strain to the elastic fibers within the aortic wall. In the aged aorta, relatively quiescent elastic fibers in the media (Avolio et al., 1998) are mechanically fragmented and those fragmented elastic fibers are stabilized and stiffened by excessive deposition of collagens and their crosslinking in the pro-inflammatory environment (Duca et al., 2016). The fragmentation of the elastic fibers in the media with aging also enhances its proteolysis by specific elastases (i.e., elastolysis), which in turn generates short peptides known as elastinderived peptides (Le Page et al., 2019). These peptides subsequently stimulate VSMC proliferation and differentiation into osteoblast-like cells (Simionescu et al., 2005) to accelerate inflammation and calcification of the aortic wall (Simionescu et al., 2005; Maurice et al., 2013; Dale et al., 2016). Importantly, exposure of the resident cells to the elastin-derived peptide further sustains chronic low-grade inflammation of the aortic wall (Le Page et al., 2019). Senescence of aged VSMCs (Monk and George, 2015) also accelerates aortic wall inflammation through the senescence-associated secretory phenotype (Chi et al., 2019) and osteoblast-like differentiation, which leads to calcium deposition in the media by upregulation of synthesis of alkaline phosphatase (ALP), bone morphogenetic protein (BMP), osteopontin (OPN), calpain-1, runt-related transcription factor (Runx-2) and collagens (Nakano-Kurimoto et al., 2009; Jiang et al., 2012; Fakhry et al., 2017). Calcium deposition around the elastic fibers is markedly increased in the aortic wall with aging (Lansing et al., 1950; Derlin et al., 2015), which further stiffens the medial layer and enhances aortic wall dysfunction (Laurent et al., 1996; Aronson, 2003).

Although arterial stiffening has historically been associated with changes in the native ECM structures, additional evidence suggests that stiffening of the resident cells [e.g., ECs and VSMCs (Gao et al., 2014; Nicholson et al., 2017; Morales-Quinones et al., 2020)] also contributes to overall stiffness of the aortic wall (Qiu et al., 2010; Sehgel et al., 2013; Sehgel et al., 2015; Leloup et al., 2019). The activity of the contractile filaments as well as the molecular signaling pathways that regulate actin polymerization and focal adhesion signaling in the VSMCs contribute to the ageassociated vascular stiffening (Nicholson et al., 2018). Interactions between VSMCs and aberrant ECM structures also play key roles in these cellular events (Zhu et al., 2012; Ribeiro-Silva et al., 2021). Excessively deposited collagens progressively acquire crosslinks (Aronson, 2003) in the intima and media, altering their structural and functional properties. Thus, disorganized ECM structures, deregulated cell-ECM interactions, and increased cellular stiffness collectively contribute to the aortic wall stiffening phenotype.

\section{Aging of Adventitia}

Adventitia not only provides structural support to the aortic wall, but also maintains its homeostasis (Tinajero and Gotlieb, 2020). Collagen fibers in the adventitia layer provide tensile strength and resilience to the cyclic deformation of the aortic wall caused by the beating heart (Thompson et al., 2002; Tsamis et al., 2013). As an axial load is placed on the vessel wall, the collagen fibers deform and straighten, exhibiting their high tensile strength. Adventitial fibroblasts synthesize and deposit collagen I and III, and these collagens increase with age and are also accompanied by stiffening of the aorta (Fleenor et al., 2010). While it is widely accepted that various adventitial cells (e.g., stem/progenitor cells, fibroblasts, arterial and lymphatic ECs, pericytes, immune cells, adipocytes, neuronal cells) and adventitial ECM molecules maintain homeostasis of the aortic wall, and deregulation of these adventitial components are proposed to contribute to pathological remodeling of the aortic wall such as atherosclerosis and AAA (outside-in theory: outer layer triggers remodeling of the aortic wall) (Stefanadis et al., 1995; Majesky et al., 2012; Majesky, 2015; Doderer et al., 2018; Tinajero and Gotlieb, 2020), the effects of aging on structure and functions of aortic adventitia have not been well-characterized compared to intima and media. A comprehensive analysis of cellular and non-cellular constituents of adventitia in young and aging aorta will be necessary to understand how they interact and crosstalk to maintain homeostasis of the aortic wall.

\section{Perspective}

Life-long mechanical loads generated by the beating left ventricle and chronic low-grade inflammation stiffen the aortic wall with age, which accelerates EC dysfunction, and subsequent remodeling of the aortic wall. Importantly, 
normally aging aortic wall (Figure 1) is not pathological, but this is predisposed to CVDs such as atherosclerosis (e.g., formation of atheromatous plaque and foam cells) and AAA (e.g., medial necrosis, dissection and rupture). To prevent the aorta from progressing into these pathological conditions, it is critical to understand the structural and functional alterations of the aging aorta. These spiral cycles lead to impaired peripheral circulation, organ failure and cardiovascular events during aging (Thorin-Trescases and Thorin, 2016) (Figure 2). Several anti-aging remedies have been explored to prevent this over the decades. For example, anti-hypertensive medications, regular aerobic exercise habits or specific diets such as Mediterranean diet may slow down the vicious cycles and decrease the risk of CVDs (Vaitkevicius et al., 1993; Seals et al., 2008; Kanaki et al., 2013; Liu et al., 2013; Santos-Parker et al., 2014; Larocca et al., 2017; Upala et al., 2017). Although these anti-aging remedies may exert the beneficial effects by attenuating chronic low-grade inflammation (Chrysohoou et al., 2004; Lesniewski et al., 2011a; Lesniewski et al., 2011b; Woods et al., 2012), more comprehensive mechanisms of age-associated aortic wall remodeling need to be explored to develop more efficient anti-aortic aging strategies. Since stiffness of the aorta, which is determined by the structures of ECM and stiffness of the resident cells, can be measured in non-invasive ways using pulse-wave-velocity (PWV) (Cavalcante et al., 2011; Laurent et al., 2016; Salvi et al., 2019), more efficient anti-aortic aging strategies such as combination of medications, fitness program and diet instruction could be rigorously explored at the clinic level.

\section{REFERENCES}

Alexander, M. R., and Owens, G. K. (2012). Epigenetic Control of Smooth Muscle Cell Differentiation and Phenotypic Switching in Vascular Development and Disease. Annu. Rev. Physiol. 74, 13-40. doi:10.1146/annurev-physiol-012110142315

Andreotti, L., Bussotti, A., Cammelli, D., Di Giovine, F., Sampognaro, S., Sterrantino, G., et al. (1985). Aortic Connective Tissue in Ageing-A Biochemical Study. Angiology 36, 872-879. doi:10.1177/000331978503601206

Antonicelli, F., Bellon, G., Debelle, L., and Hornebeck, W. (2007). Elastin-Elastases and Inflamm-Aging. Curr. Top. Dev. Biol. 79, 99-155. doi:10.1016/s00702153(06)79005-6

Aronson, D. (2003). Cross-linking of Glycated Collagen in the Pathogenesis of Arterial and Myocardial Stiffening of Aging and Diabetes. J. Hypertens. 21, 3-12. doi:10.1097/00004872-200301000-00002

Avolio, A., Jones, D., and Tafazzoli-Shadpour, M. (1998). Quantification of Alterations in Structure and Function of Elastin in the Arterial media. Hypertension 32, 170-175. doi:10.1161/01.hyp.32.1.170

Beenakker, J.-W. M., Ashcroft, B. A., Lindeman, J. H. N., and Oosterkamp, T. H. (2012). Mechanical Properties of the Extracellular Matrix of the Aorta Studied by Enzymatic Treatments. Biophysical J. 102, 1731-1737. doi:10.1016/j.bpj. 2012.03.041

Belz, G. G. (1995). Elastic Properties and Windkessel Function of the Human Aorta. Cardiovasc. Drug Ther. 9, 73-83. doi:10.1007/bf00877747

Bhayadia, R., Schmidt, B. M. W., Melk, A., and Hömme, M. (2016). SenescenceInduced Oxidative Stress Causes Endothelial Dysfunction. Gerona 71, 161-169. doi:10.1093/gerona/glv008

Birch, H. L. (2018). Extracellular Matrix and Ageing. Subcell Biochem. 90, 169-190. doi:10.1007/978-981-13-2835-0_7

\section{SUMMARY}

Age-associated ECM alterations play crucial roles in the progression of aortic aging. Targeting altered ECM structures and cell-ECM interactions in the aortic wall using combinations of ECM and cytoskeleton modifiers can be a promising therapeutic strategy for aortic pathologies. Further functional characterization of the ECM alterations and cell-ECM interactions in the aged aorta will provide a new framework to develop more efficient therapies for aortic aging and CVDs.

\section{AUTHOR CONTRIBUTIONS}

All authors listed have made a substantial, direct, and intellectual contribution to the work and approved it for publication.

\section{FUNDING}

This work was supported by funds from NIH R21AG054830 (to AM, to TM), R01HL139638 (to AM, to TM), R21AG062893 (to $\mathrm{AM}$, to TM), R01HL142578 (to AM, to TM), and AHA 18TPA34170129 (to AM).

\section{ACKNOWLEDGMENTS}

The authors thank Joy Lincoln for critical review of the manuscript.

Bochaton-Piallat, M.-L., Clowes, A. W., Clowes, M. M., Fischer, J. W., Redard, M., Gabbiani, F., et al. (2001). Cultured Arterial Smooth Muscle Cells Maintain Distinct Phenotypes when Implanted into Carotid Artery. Atvb 21, 949-954. doi:10.1161/01.atv.21.6.949

Bochaton-Piallat, M. L., Gabbiani, F., Ropraz, P., and Gabbiani, G. (1993). Age Influences the Replicative Activity and the Differentiation Features of Cultured Rat Aortic Smooth Muscle Cell Populations and Clones. Arterioscler Thromb. 13, 1449-1455. doi:10.1161/01.atv.13.10.1449

Brüel, A., and Oxlund, H. (1996). Changes in Biomechanical Properties, Composition of Collagen and Elastin, and Advanced Glycation Endproducts of the Rat Aorta in Relation to Age. Atherosclerosis 127, 155-165. doi:10.1016/ s0021-9150(96)05947-3

Buford, T. W. (2016). Hypertension and Aging. Ageing Res. Rev. 26, 96-111. doi:10. 1016/j.arr.2016.01.007

Busse, R., and Fleming, I. (2006). Vascular Endothelium and Blood Flow. Handb Exp. Pharmacol. 176, 43-78. doi:10.1007/3-540-36028-x_2

Cannatà, A., Marcon, G., Cimmino, G., Camparini, L., Ciucci, G., Sinagra, G., et al. (2017). Role of Circulating Factors in Cardiac Aging. J. Thorac. Dis. 9, S17-S29. doi:10.21037/jtd.2017.03.95

Cavalcante, J. L., Lima, J. A. C., Redheuil, A., and Al-Mallah, M. H. (2011). Aortic Stiffness. J. Am. Coll. Cardiol. 57, 1511-1522. doi:10.1016/j.jacc.2010.12.017

Chen, M. A., Kawakubo, M., Colletti, P. M., Xu, D., Labree Dustin, L., Detrano, R., et al. (2013). Effect of Age on Aortic Atherosclerosis. J. Geriatr. Cardiol. 10, 135-140. doi:10.3969/j.issn.1671-5411.2013.02.005

Chi, C., Li, D.-J., Jiang, Y.-J., Tong, J., Fu, H., Wu, Y.-H., et al. (2019). Vascular Smooth Muscle Cell Senescence and Age-Related Diseases: State of the Art. Biochim. Biophys. Acta (Bba) - Mol. Basis Dis. 1865, 1810-1821. doi:10.1016/j. bbadis.2018.08.015

Chrysohoou, C., Panagiotakos, D. B., Pitsavos, C., Das, U. N., and Stefanadis, C. (2004). Adherence to the Mediterranean Diet Attenuates Inflammation and 
Coagulation Process in Healthy Adults. J. Am. Coll. Cardiol. 44, 152-158. doi:10.1016/j.jacc.2004.03.039

Clark, J. M., and Glagov, S. (1985). Transmural Organization of the Arterial media. The Lamellar Unit Revisited. Arteriosclerosis 5, 19-34. doi:10.1161/01.atv.5.1.19

Cocciolone, A. J., Hawes, J. Z., Staiculescu, M. C., Johnson, E. O., Murshed, M., and Wagenseil, J. E. (2018). Elastin, Arterial Mechanics, and Cardiovascular Disease. Am. J. Physiology-Heart Circulatory Physiol. 315, H189-H205. doi:10.1152/ajpheart.00087.2018

Collins, C., Osborne, L. D., Guilluy, C., Chen, Z., O'Brien, E. T., 3rd, Reader, J. S., et al. (2014a). Haemodynamic and Extracellular Matrix Cues Regulate the Mechanical Phenotype and Stiffness of Aortic Endothelial Cells. Nat. Commun. 5, 3984. doi:10.1038/ncomms4984

Collins, J. A., Munoz, J.-V., Patel, T. R., Loukas, M., and Tubbs, R. S. (2014b). The Anatomy of the Aging Aorta. Clin. Anat. 27, 463-466. doi:10.1002/ca.22384

Dale, M. A., Xiong, W., Carson, J. S., Suh, M. K., Karpisek, A. D., Meisinger, T. M., et al. (2016). Elastin-Derived Peptides Promote Abdominal Aortic Aneurysm Formation by Modulating M1/M2 Macrophage Polarization. J.I. 196, 4536-4543. doi:10.4049/jimmunol.1502454

Davis, G. E., and Senger, D. R. (2005). Endothelial Extracellular Matrix. Circ. Res. 97, 1093-1107. doi:10.1161/01.res.0000191547.64391.e3

Davis, G. E., and Senger, D. R. (2008). Extracellular Matrix Mediates a Molecular Balance between Vascular Morphogenesis and Regression. Curr. Opin. Hematol. 15, 197-203. doi:10.1097/moh.0b013e3282fcc321

Derlin, T., Janssen, T., Salamon, J., Veldhoen, S., Busch, J. D., Schön, G., et al. (2015). Age-related Differences in the Activity of Arterial mineral Deposition and Regional Bone Metabolism: a 18F-Sodium Fluoride Positron Emission Tomography Study. Osteoporos. Int. 26, 199-207. doi:10.1007/s00198-0142839-6

Dernellis, J., and Panaretou, M. (2005). Aortic Stiffness Is an Independent Predictor of Progression to Hypertension in Nonhypertensive Subjects. Hypertension 45, 426-431. doi:10.1161/01.hyp.0000157818.58878.93

Di Tullio, M. R., Homma, S., Jin, Z., and Sacco, R. L. (2008). Aortic Atherosclerosis, Hypercoagulability, and Stroke. J. Am. Coll. Cardiol. 52, 855-861. doi:10.1016/j. jacc.2008.04.062

Dingemans, K. P., Teeling, P., Lagendijk, J. H., and Becker, A. E. (2000). Extracellular Matrix of the Human Aortic media: an Ultrastructural Histochemical and Immunohistochemical Study of the Adult Aortic media. Anat. Rec. 258, 1-14. doi:10.1002/(sici)1097-0185(20000101)258:1<1::aid$\operatorname{ar} 1>3.0 . \operatorname{co} ; 2-7$

Doderer, S. A., Gäbel, G., Kokje, V. B. C., Northoff, B. H., Holdt, L. M., Hamming, J. F., et al. (2018). Adventitial Adipogenic Degeneration Is an Unidentified Contributor to Aortic wall Weakening in the Abdominal Aortic Aneurysm. J. Vasc. Surg. 67, 1891-1900. doi:10.1016/j.jvs.2017.05.088

Donato, A. J., Machin, D. R., and Lesniewski, L. A. (2018). Mechanisms of Dysfunction in the Aging Vasculature and Role in Age-Related Disease. Circ. Res. 123, 825-848. doi:10.1161/circresaha.118.312563

Donato, A. J., Morgan, R. G., Walker, A. E., and Lesniewski, L. A. (2015). Cellular and Molecular Biology of Aging Endothelial Cells. J. Mol. Cell Cardiol. 89, 122-135. doi:10.1016/j.yjmcc.2015.01.021

Duca, L., Blaise, S., Romier, B., Laffargue, M., Gayral, S., El Btaouri, H., et al. (2016). Matrix Ageing and Vascular Impacts: Focus on Elastin Fragmentation. Cardiovasc. Res. 110, 298-308. doi:10.1093/cvr/cvw061

Erusalimsky, J. D., and Kurz, D. J. (2006). Endothelial Cell Senescence. Handb Exp. Pharmacol. 106, 213-248. doi:10.1007/3-540-36028-x_7

Fakhry, M., Roszkowska, M., Briolay, A., Bougault, C., Guignandon, A., DiazHernandez, J. I., et al. (2017). TNAP Stimulates Vascular Smooth Muscle Cell Trans-differentiation into Chondrocytes through Calcium Deposition and BMP-2 Activation: Possible Implication in Atherosclerotic Plaque Stability. Biochim. Biophys. Acta (Bba) - Mol. Basis Dis. 1863, 643-653. doi:10.1016/j. bbadis.2016.12.003

Falkenberg, K. D., Rohlenova, K., Luo, Y., and Carmeliet, P. (2019). The Metabolic Engine of Endothelial Cells. Nat. Metab. 1, 937-946. doi:10.1038/s42255-019$0117-9$

Fels, J., Jeggle, P., Kusche-Vihrog, K., and Oberleithner, H. (2012). Cortical Actin Nanodynamics Determines Nitric Oxide Release in Vascular Endothelium. PLoS One 7, e41520. doi:10.1371/journal.pone.0041520

Ferlosio, A., Arcuri, G., Doldo, E., Scioli, M. G., De Falco, S., Spagnoli, L. G., et al. (2012). Age-related Increase of Stem Marker Expression Influences Vascular
Smooth Muscle Cell Properties. Atherosclerosis 224, 51-57. doi:10.1016/j. atherosclerosis.2012.07.016

Fleenor, B. S., Marshall, K. D., Durrant, J. R., Lesniewski, L. A., and Seals, D. R. (2010). Arterial Stiffening with Ageing Is Associated with Transforming Growth Factor-B1-Related Changes in Adventitial Collagen: Reversal by Aerobic Exercise. J. Physiol. 588, 3971-3982. doi:10.1113/jphysiol.2010.194753

Franceschi, C., Garagnani, P., Morsiani, C., Conte, M., Santoro, A., Grignolio, A., et al. (2018). The Continuum of Aging and Age-Related Diseases: Common Mechanisms but Different Rates. Front. Med. 5, 61. doi:10.3389/fmed.2018. 00061

Frantz, C., Stewart, K. M., and Weaver, V. M. (2010). The Extracellular Matrix at a Glance. J. Cel Sci 123, 4195-4200. doi:10.1242/jcs.023820

Gao, Y. Z., Saphirstein, R. J., Yamin, R., Suki, B., and Morgan, K. G. (2014). Aging Impairs Smooth Muscle-Mediated Regulation of Aortic Stiffness: a Defect in Shock Absorption Function? Am. J. Physiology-Heart Circulatory Physiol. 307, H1252-H1261. doi:10.1152/ajpheart.00392.2014

Gariepy, J., Salomon, J., Denarie', N., Laskri, F., Me'gnien, J. L., Levenson, J., et al. (1998). Sex and Topographic Differences in Associations between Large-Artery Wall Thickness and Coronary Risk Profile in a French Working Cohort. Atvb 18, 584-590. doi:10.1161/01.atv.18.4.584

Golledge, J. (2019). Abdominal Aortic Aneurysm: Update on Pathogenesis and Medical Treatments. Nat. Rev. Cardiol. 16, 225-242. doi:10.1038/s41569-0180114-9

Guyton, D. L., Lindsay, K. L., and Dao, D. T. (1983). Pediatric Ophthalmology. Ophthalmology 90, 234-246. doi:10.1016/s0161-6420(83)80140-7

Ha, H., Ziegler, M., Welander, M., Bjarnegård, N., Carlhäll, C.-J., Lindenberger, M., et al. (2018). Age-Related Vascular Changes Affect Turbulence in Aortic Blood Flow. Front. Physiol. 9, 36. doi:10.3389/fphys.2018.00036

Halabi, C. M., and Kozel, B. A. (2020). Vascular Elastic Fiber Heterogeneity in Health and Disease. Curr. Opin. Hematol. 27, 190-196. doi:10.1097/moh. 0000000000000578

Hallmann, R., Horn, N., Selg, M., Wendler, O., Pausch, F., and Sorokin, L. M. (2005). Expression and Function of Laminins in the Embryonic and Mature Vasculature. Physiol. Rev. 85, 979-1000. doi:10.1152/physrev. 00014.2004

Halper, J., and Kjaer, M. (2014). Basic Components of Connective Tissues and Extracellular Matrix: Elastin, Fibrillin, Fibulins, Fibrinogen, Fibronectin, Laminin, Tenascins and Thrombospondins. Adv. Exp. Med. Biol. 802, 31-47. doi:10.1007/978-94-007-7893-1_3

Hays, T. T., Ma, B., Zhou, N., Stoll, S., Pearce, W. J., and Qiu, H. (2018). Vascular Smooth Muscle Cells Direct Extracellular Dysregulation in Aortic Stiffening of Hypertensive Rats. Aging Cell 17, e12748. doi:10.1111/acel.12748

Hedtke, T., Schräder, C. U., Heinz, A., Hoehenwarter, W., Brinckmann, J., Groth, T., et al. (2019). A Comprehensive Map of Human Elastin Cross-linking during Elastogenesis. FEBS J. 286, 3594-3610. doi:10.1111/febs.14929

Heidenreich, P. A., Trogdon, J. G., Khavjou, O. A., Butler, J., Dracup, K., Ezekowitz, M. D., et al. (2011). Forecasting the Future of Cardiovascular Disease in the United States: a Policy Statement from the American Heart Association. Circulation 123, 933-944. doi:10.1161/cir.0b013e31820a55f5(

Heinz, A. (2021). Elastic Fibers during Aging and Disease. Ageing Res. Rev. 66, 101255. doi:10.1016/j.arr.2021.101255

Hohensinner, P. J., Kaun, C., Buchberger, E., Ebenbauer, B., Demyanets, S., Huk, I., et al. (2016). Age Intrinsic Loss of Telomere protection via TRF1 Reduction in Endothelial Cells. Biochim. Biophys. Acta (Bba) - Mol. Cel Res. 1863, 360-367. doi:10.1016/j.bbamcr.2015.11.034

Huynh, J., Nishimura, N., Rana, K., Peloquin, J. M., Califano, J. P., Montague, C. R., et al. (2011). Age-related Intimal Stiffening Enhances Endothelial Permeability and Leukocyte Transmigration. Sci. Transl Med. 3, 112ra122. doi:10.1126/ scitranslmed.3002761

Jaffer, F. A., O’Donnell, C. J., Larson, M. G., Chan, S. K., Kissinger, K. V., Kupka, M. J., et al. (2002). Age and Sex Distribution of Subclinical Aortic Atherosclerosis. Atvb 22, 849-854. doi:10.1161/01.atv.0000012662.29622.00

Jana, S., Hu, M., Shen, M., and Kassiri, Z. (2019). Extracellular Matrix, Regional Heterogeneity of the Aorta, and Aortic Aneurysm. Exp. Mol. Med. 51, 1-15. doi:10.1038/s12276-019-0286-3

Jiang, L., Zhang, J., Monticone, R. E., Telljohann, R., Wu, J., Wang, M., et al. (2012). Calpain-1 Regulation of Matrix Metalloproteinase 2 Activity in Vascular Smooth Muscle Cells Facilitates Age-Associated Aortic wall Calcification 
and Fibrosis. Hypertension 60, 1192-1199. doi:10.1161/hypertensionaha.112. 196840

Jolly, A. J., Lu, S., Strand, K. A., Dubner, A. M., Mutryn, M. F., Nemenoff, R. A., et al. (2021). Heterogeneous Subpopulations of Adventitial Progenitor Cells Regulate Vascular Homeostasis and Pathological Vascular Remodeling. Cardiovasc. Res. 14, cvab174. doi:10.1093/cvr/cvab174

Kanaki, A. I., Sarafidis, P. A., Georgianos, P. I., Kanavos, K., Tziolas, I. M., Zebekakis, P. E., et al. (2013). Effects of Low-Dose Atorvastatin on Arterial Stiffness and central Aortic Pressure Augmentation in Patients with Hypertension and Hypercholesterolemia. Am. J. Hypertens. 26, 608-616. doi:10.1093/ajh/hps098

Kang, J. S., and Yang, Y. R. (2020). Circulating Plasma Factors Involved in Rejuvenation. Aging (Albany NY) 12, 23394-23408. doi:10.18632/aging.103933

Kiss, T., Tarantini, S., Csipo, T., Balasubramanian, P., Nyúl-Tóth, Á., Yabluchanskiy, A., et al. (2020). Circulating Anti-geronic Factors from Heterochonic Parabionts Promote Vascular Rejuvenation in Aged Mice: Transcriptional Footprint of Mitochondrial protection, Attenuation of Oxidative Stress, and rescue of Endothelial Function by Young Blood. Geroscience 42, 727-748. doi:10.1007/s11357-020-00180-6

Kohn, J. C., Lampi, M. C., and Reinhart-King, C. A. (2015). Age-related Vascular Stiffening: Causes and Consequences. Front. Genet. 06, 112. doi:10.3389/fgene. 2015.00112

Krettek, A., Sukhova, G. K., and Libby, P. (2003). Elastogenesis in Human Arterial Disease. Atvb 23, 582-587. doi:10.1161/01.atv.0000064372.78561.a5

Kronzon, I., and Tunick, P. A. (2006). Aortic Atherosclerotic Disease and Stroke. Circulation 114, 63-75. doi:10.1161/circulationaha.105.593418

Krouwer, V. J. D., Hekking, L. H. P., Langelaar-Makkinje, M., Regan-Klapisz, E., and Post, J. (2012). Endothelial Cell Senescence Is Associated with Disrupted Cell-Cell Junctions and Increased Monolayer Permeability. Vasc. Cel 4, 12. doi:10.1186/2045-824x-4-12

Krüger-Genge, A., Blocki, A., Franke, R. P., and Jung, F. (2019). Vascular Endothelial Cell Biology: An Update. Int. J. Mol. Sci. 20, 4411. doi:10.3390/ ijms20184411

Kutkut, I., Meens, M. J., Mckee, T. A., Bochaton-Piallat, M.-L., and Kwak, B. R. (2015). Lymphatic Vessels: an Emerging Actor in Atherosclerotic Plaque Development. Eur. J. Clin. Invest. 45, 100-108. doi:10.1111/eci.12372

Lacolley, P., Regnault, V., Segers, P., and Laurent, S. (2017). Vascular Smooth Muscle Cells and Arterial Stiffening: Relevance in Development, Aging, and Disease. Physiol. Rev. 97, 1555-1617. doi:10.1152/physrev.00003.2017

Lakatta, E. G., and Levy, D. (2003a). Arterial and Cardiac Aging: Major Shareholders in Cardiovascular Disease Enterprises. Circulation 107, 139-146. doi:10.1161/01.cir.0000048892.83521.58

Lansing, A. I., Alex, M., and Rosenthal, T. B. (1950). Calcium and Elastin in Human Arteriosclerosis. J. Gerontol. 5, 112-119. doi:10.1093/geronj/5.2.112

Lantz, J., Renner, J., Länne, T., and Karlsson, M. (2015). Is Aortic wall Shear Stress Affected by Aging? an Image-Based Numerical Study with Two Age Groups. Med. Eng. Phys. 37, 265-271. doi:10.1016/j.medengphy.2014.12.011

Larocca, T. J., Martens, C. R., and Seals, D. R. (2017). Nutrition and Other Lifestyle Influences on Arterial Aging. Ageing Res. Rev. 39, 106-119. doi:10.1016/j.arr. 2016.09.002

Laurent, S., Lacolley, P., Girerd, X., Boutouyrie, P., Bezie, Y., and Safar, M. (1996). Arterial Stiffening: Opposing Effects of Age- and Hypertension-Associated Structural Changes. Can. J. Physiol. Pharmacol. 74, 842-849. doi:10.1139/ y96-075

Laurent, S., Marais, L., and Boutouyrie, P. (2016). The Noninvasive Assessment of Vascular Aging. Can. J. Cardiol. 32, 669-679. doi:10.1016/j.cjca.2016.01.039

Le Page, A., Khalil, A., Vermette, P., Frost, E. H., Larbi, A., Witkowski, J. M., et al. (2019). The Role of Elastin-Derived Peptides in Human Physiology and Diseases. Matrix Biol. 84, 81-96. doi:10.1016/j.matbio.2019.07.004

Leloup, A. J. A., Van Hove, C. E., De Moudt, S., De Meyer, G. R. Y., De Keulenaer, G. W., and Fransen, P. (2019). Vascular Smooth Muscle Cell Contraction and Relaxation in the Isolated Aorta: a Critical Regulator of Large Artery Compliance. Physiol. Rep. 7, e13934. doi:10.14814/phy2.13934

Lesniewski, L. A., Durrant, J. R., Connell, M. L., Folian, B. J., Donato, A. J., and Seals, D. R. (2011a). Salicylate Treatment Improves Age-Associated Vascular Endothelial Dysfunction: Potential Role of Nuclear Factor B and Forkhead Box O Phosphorylation. Journals Gerontol. Ser. A: Biol. Sci. Med. Sci. 66A, 409-418. doi:10.1093/gerona/glq233
Lesniewski, L. A., Durrant, J. R., Connell, M. L., Henson, G. D., Black, A. D., Donato, A. J., et al. (2011b). Aerobic Exercise Reverses Arterial Inflammation with Aging in Mice. Am. J. Physiology-Heart Circulatory Physiol. 301, H1025-H1032. doi:10.1152/ajpheart.01276.2010

Li, Z., Froehlich, J., Galis, Z. S., and Lakatta, E. G. (1999). Increased Expression of Matrix Metalloproteinase-2 in the Thickened Intima of Aged Rats. Hypertension 33, 116-123. doi:10.1161/01.hyp.33.1.116

Liao, D., Arnett, D. K., Tyroler, H. A., Riley, W. A., Chambless, L. E., Szklo, M., et al. (1999). Arterial Stiffness and the Development of Hypertension. Hypertension 34, 201-206. doi:10.1161/01.hyp.34.2.201

Liu, M., Li, G.-L., Li, Y., and Wang, J.-G. (2013). Effects of Various Antihypertensive Drugs on Arterial Stiffness and Wave Reflections. Pulse 1, 97-107. doi:10.1159/000354108

Lyck Hansen, M., Beck, H. C., Irmukhamedov, A., Jensen, P. S., Olsen, M. H., and Rasmussen, L. M. (2015). Proteome Analysis of Human Arterial Tissue Discloses Associations between the Vascular Content of Small Leucine-Rich Repeat Proteoglycans and Pulse Wave Velocity. Atvb 35, 1896-1903. doi:10. 1161/atvbaha.114.304706

Maier, J. A. M., Voulalas, P., Roeder, D., and Maciag, T. (1990). Extension of the Life-Span of Human Endothelial Cells by an Interleukin-1aAntisense Oligomer. Science 249, 1570-1574. doi:10.1126/science.2218499

Majesky, M. W. (2015). Adventitia and Perivascular Cells. Arterioscler Thromb. Vasc. Biol. 35, e31-5. doi:10.1161/ATVBAHA.115.306088

Majesky, M. W., Dong, X. R., Hoglund, V., Daum, G., and Mahoney, Jr., W. M., Jr. (2012). The Adventitia: a Progenitor Cell Niche for the Vessel wall. Cells Tissues Organs 195, 73-81. doi:10.1159/000331413

Majesky, M. W., Dong, X. R., Hoglund, V., Mahoney, W. M., Jr., and Daum, G. (2011). The Adventitia. Arterioscler Thromb. Vasc. Biol. 31, 1530-1539. doi:10. 1161/atvbaha.110.221549

Maurice, P., Blaise, S., Gayral, S., Debelle, L., Laffargue, M., Hornebeck, W., et al. (2013). Elastin Fragmentation and Atherosclerosis Progression: the Elastokine Concept. Trends Cardiovasc. Med. 23, 211-221. doi:10.1016/j.tcm.2012.12.004

Mccullagh, K. G., Duance, V. C., and Bishop, K. A. (1980). The Distribution of Collagen Types I, III and V (AB) in normal and Atherosclerotic Human Aorta. J. Pathol. 130, 45-55. doi:10.1002/path.1711300107

Mceniery, C. M., Wilkinson, I. B., and Avolio, A. P. (2007). Age, Hypertension and Arterial Function. Clin. Exp. Pharmacol. Physiol. 34, 665-671. doi:10.1111/j. 1440-1681.2007.04657.x

Méndez-Barbero, N., Gutiérrez-Muñoz, C., and Blanco-Colio, L. M. (2021). Cellular Crosstalk between Endothelial and Smooth Muscle Cells in Vascular Wall Remodeling. Int. J. Mol. Sci. 22, 7284. doi:10.3390/ijms22147284

Michiels, C. (2003). Endothelial Cell Functions. J. Cel. Physiol. 196, 430-443. doi:10.1002/jcp.10333

Miller, S. J., Watson, W. C., Kerr, K. A., Labarrere, C. A., Chen, N. X., Deeg, M. A., et al. (2007). Development of Progressive Aortic Vasculopathy in a Rat Model of Aging. Am. J. Physiology-Heart Circulatory Physiol. 293, H2634-H2643. doi:10. 1152/ajpheart.00397.2007

Mitchell, G. F., Hwang, S.-J., Vasan, R. S., Larson, M. G., Pencina, M. J., Hamburg, N. M., et al. (2010). Arterial Stiffness and Cardiovascular Events. Circulation 121, 505-511. doi:10.1161/circulationaha.109.886655

Monk, B. A., and George, S. J. (2015). The Effect of Ageing on Vascular Smooth Muscle Cell Behaviour - A Mini-Review. Gerontology 61, 416-426. doi:10.1159/ 000368576

Moon, S.-K., Cha, B.-Y., and Kim, C.-H. (2003). In Vitro cellular Aging Is Associated with Enhanced Proliferative Capacity, G1 Cell Cycle Modulation, and Matrix Metalloproteinase-9 Regulation in Mouse Aortic Smooth Muscle Cells. Arch. Biochem. Biophys. 418, 39-48. doi:10.1016/s0003-9861(03)00402-8

Morales-Quinones, M., Ramirez-Perez, F. I., Foote, C. A., Ghiarone, T., FerreiraSantos, L., Bloksgaard, M., et al. (2020). LIMK (LIM Kinase) Inhibition Prevents Vasoconstriction- and Hypertension-Induced Arterial Stiffening and Remodeling. Hypertension 76, 393-403. doi:10.1161/hypertensionaha.120. 15203

Morgan, R. G., Donato, A. J., and Walker, A. E. (2018). Telomere Uncapping and Vascular Aging. Am. J. Physiology-Heart Circulatory Physiol. 315, H1-H5. doi:10.1152/ajpheart.00008.2018

Movat, H. Z., More, R. H., and Haust, M. D. (1958). The Diffuse Intimal Thickening of the Human Aorta with Aging. Am. J. Pathol. 34, 1023-1031. 
Nakano-Kurimoto, R., Ikeda, K., Uraoka, M., Nakagawa, Y., Yutaka, K., Koide, M., et al. (2009). Replicative Senescence of Vascular Smooth Muscle Cells Enhances the Calcification through Initiating the Osteoblastic Transition. Am. J. Physiology-Heart Circulatory Physiol. 297, H1673-H1684. doi:10.1152/ ajpheart.00455.2009

Nakayama, K. H., Hou, L., and Huang, N. F. (2014). Role of Extracellular Matrix Signaling Cues in Modulating Cell Fate Commitment for Cardiovascular Tissue Engineering. Adv. Healthc. Mater. 3, 628-641. doi:10.1002/adhm.201300620

Nascimento, R. A., Possomato-Vieira, J. S., Bonacio, G. F., Rizzi, E., and DiasJunior, C. A. (2019). Reductions of Circulating Nitric Oxide Are Followed by Hypertension during Pregnancy and Increased Activity of Matrix Metalloproteinases-2 and -9 in Rats. Cells 8, 1402. doi:10.3390/cells8111402

Nava, E., and Llorens, S. (2019). The Local Regulation of Vascular Function: From an Inside-Outside to an Outside-Inside Model. Front. Physiol. 10, 729. doi:10. 3389/fphys.2019.00729

Nicholson, C. J., Singh, K., Saphirstein, R. J., Gao, Y. Z., Li, Q., Chiu, J. G., et al. (2018). Reversal of Aging-Induced Increases in Aortic Stiffness by Targeting Cytoskeletal Protein-Protein Interfaces. J. Am. Heart Assoc. 7, e008926. doi:10. 1161/JAHA.118.008926

Nicholson, C. J., Seta, F., Lee, S., and Morgan, K. G. (2017). MicroRNA-203 Mimics Age-Related Aortic Smooth Muscle Dysfunction of Cytoskeletal Pathways. J. Cel. Mol. Med. 21, 81-95. doi:10.1111/jcmm.12940

North, B. J., and Sinclair, D. A. (2012). The Intersection between Aging and Cardiovascular Disease. Circ. Res. 110, 1097-1108. doi:10.1161/circresaha.111. 246876

Oyama, N., Gona, P., Salton, C. J., Chuang, M. L., Jhaveri, R. R., Blease, S. J., et al. (2008). Differential Impact of Age, Sex, and Hypertension on Aortic Atherosclerosis. Atvb 28, 155-159. doi:10.1161/atvbaha.107.153544

Ozen, G., Daci, A., Norel, X., and Topal, G. (2015). Human Perivascular Adipose Tissue Dysfunction as a Cause of Vascular Disease: Focus on Vascular Tone and wall Remodeling. Eur. J. Pharmacol. 766, 16-24. doi:10.1016/j.ejphar.2015. 09.012

Ozsvar, J., Yang, C., Cain, S. A., Baldock, C., Tarakanova, A., and Weiss, A. S. (2021). Tropoelastin and Elastin Assembly. Front. Bioeng. Biotechnol. 9, 643110. doi:10.3389/fbioe.2021.643110

Paar, M., Pavenstädt, H., Kusche-Vihrog, K., Drüppel, V., Oberleithner, H., and Kliche, K. (2014). Endothelial Sodium Channels Trigger Endothelial Salt Sensitivity with Aging. Hypertension 64, 391-396. doi:10.1161/ hypertensionaha. 114.03348

Paneni, F., Costantino, S., and Cosentino, F. (2015). Molecular Pathways of Arterial Aging. Clin. Sci. (Lond) 128, 69-79. doi:10.1042/cs20140302

Paneni, F., Diaz Cañestro, C., Libby, P., Lüscher, T. F., and Camici, G. G. (2017). The Aging Cardiovascular System. J. Am. Coll. Cardiol. 69, 1952-1967. doi:10. 1016/j.jacc.2017.01.064

Pantsulaia, I., Ciszewski, W. M., and Niewiarowska, J. (2016). Senescent Endothelial Cells: Potential Modulators of Immunosenescence and Ageing. Ageing Res. Rev. 29, 13-25. doi:10.1016/j.arr.2016.05.011

Peralta, C. A., Adeney, K. L., Shlipak, M. G., Jacobs, D., Jr., Duprez, D., Bluemke, D., et al. (2010). Structural and Functional Vascular Alterations and Incident Hypertension in Normotensive Adults: the Multi-Ethnic Study of Atherosclerosis. Am. J. Epidemiol. 171, 63-71. doi:10.1093/aje/kwp319

Peshkova, I. O., Schaefer, G., and Koltsova, E. K. (2016). Atherosclerosis and Aortic Aneurysm - Is Inflammation a Common Denominator? FEBS J. 283, 1636-1652. doi:10.1111/febs.13634

Pober, J. S., Min, W., and Bradley, J. R. (2009). Mechanisms of Endothelial Dysfunction, Injury, and Death. Annu. Rev. Pathol. Mech. Dis. 4, 71-95. doi:10.1146/annurev.pathol.4.110807.092155

Qiu, H., Depre, C., Ghosh, K., Resuello, R. G., Natividad, F. F., Rossi, F., et al. (2007). Mechanism of Gender-specific Differences in Aortic Stiffness with Aging in Nonhuman Primates. Circulation 116, 669-676. doi:10.1161/ circulationaha.107.689208

Qiu, H., Zhu, Y., Sun, Z., Trzeciakowski, J. P., Gansner, M., Depre, C., et al. (2010). Short Communication: Vascular Smooth Muscle Cell Stiffness as a Mechanism for Increased Aortic Stiffness with Aging. Circ. Res. 107, 615-619. doi:10.1161/ circresaha.110.221846

Ribeiro-Silva, J. C., Nolasco, P., Krieger, J. E., and Miyakawa, A. A. (2021). Dynamic Crosstalk between Vascular Smooth Muscle Cells and the Aged Extracellular Matrix. Int. J. Mol. Sci. 22, 10175. doi:10.3390/ijms221810175
Ross, R., and Glomset, J. A. (1973). Atherosclerosis and the Arterial Smooth Muscle Cell. Science 180, 1332-1339. doi:10.1126/science.180.4093.1332

Rybtsova, N., Berezina, T., Kagansky, A., and Rybtsov, S. (2020). Can BloodCirculating Factors Unveil and Delay Your Biological Aging? Biomedicines 8, 615. doi:10.3390/biomedicines 8120615

Sahu, A., Mamiya, H., Shinde, S. N., Cheikhi, A., Winter, L. L., Vo, N. V., et al. (2018). Age-related Declines in a-Klotho Drive Progenitor Cell Mitochondrial Dysfunction and Impaired Muscle Regeneration. Nat. Commun. 9, 4859. doi:10.1038/s41467-018-07253-3

Sakalihasan, N., Michel, J.-B., Katsargyris, A., Kuivaniemi, H., Defraigne, J.-O., Nchimi, A., et al. (2018). Abdominal Aortic Aneurysms. Nat. Rev. Dis. Primers 4, 34. doi:10.1038/s41572-018-0030-7

Salvi, P., Scalise, F., Rovina, M., Moretti, F., Salvi, L., Grillo, A., et al. (2019). Noninvasive Estimation of Aortic Stiffness through Different Approaches. Hypertension 74, 117-129. doi:10.1161/hypertensionaha.119.12853

Sandberg, L. B., Soskel, N. T., and Leslie, J. G. (1981). Elastin Structure, Biosynthesis, and Relation to Disease States. N. Engl. J. Med. 304, 566-579. doi:10.1056/nejm198103053041004

Sandoo, A., Veldhuijzen van Zanten, J. J. C. S., Metsios, G. S., Carroll, D., and Kitas, G. D. (2010). The Endothelium and its Role in Regulating Vascular Tone. Tocmj 4, 302-312. doi:10.2174/1874192401004010302

Santos-Parker, J. R., Larocca, T. J., and Seals, D. R. (2014). Aerobic Exercise and Other Healthy Lifestyle Factors that Influence Vascular Aging. Adv. Physiol. Educ. 38, 296-307. doi:10.1152/advan.00088.2014

Schwartz, S. M., Deblois, D., and O'Brien, E. R. M. (1995). The Intima. Circ. Res. 77, 445-465. doi:10.1161/01.res.77.3.445

Seals, D. R., Desouza, C. A., Donato, A. J., and Tanaka, H. (2008). Habitual Exercise and Arterial Aging. J. Appl. Physiol. 105, 1323-1332. doi:10.1152/japplphysiol. 90553.2008

Sehgel, N. L., Vatner, S. F., and Meininger, G. A. (2015). "Smooth Muscle Cell Stiffness Syndrome"-Revisiting the Structural Basis of Arterial Stiffness. Front. Physiol. 6, 335. doi:10.3389/fphys.2015.00335

Sehgel, N. L., Zhu, Y., Sun, Z., Trzeciakowski, J. P., Hong, Z., Hunter, W. C., et al. (2013). Increased Vascular Smooth Muscle Cell Stiffness: a Novel Mechanism for Aortic Stiffness in Hypertension. Am. J. Physiology-Heart Circulatory Physiol. 305, H1281-H1287. doi:10.1152/ajpheart.00232. 2013

Shekhonin, B. V., Domogatsky, S. P., Idelson, G. L., Koteliansky, V. E., and Rukosuev, V. S. (1987). Relative Distribution of Fibronectin and Type I, III, IV, V Collagens in normal and Atherosclerotic Intima of Human Arteries. Atherosclerosis 67, 9-16. doi:10.1016/0021-9150(87)90259-0

Simionescu, A., Philips, K., and Vyavahare, N. (2005). Elastin-derived Peptides and TGF-B1 Induce Osteogenic Responses in Smooth Muscle Cells. Biochem. Biophysical Res. Commun. 334, 524-532. doi:10.1016/j.bbrc.2005.06.119

Smith, L. K., He, Y., Park, J.-S., Bieri, G., Snethlage, C. E., Lin, K., et al. (2015). ß2microglobulin Is a Systemic Pro-aging Factor that Impairs Cognitive Function and Neurogenesis. Nat. Med. 21, 932-937. doi:10.1038/nm.3898

Spina, M., and Garbin, G. (1976). Age-related Chemical Changes in Human Elastins from Non-atherosclerotic Areas of Thoracic Aorta. Atherosclerosis 24, 267-279. doi:10.1016/0021-9150(76)90082-4

Spinetti, G., Wang, M., Monticone, R., Zhang, J., Zhao, D., and Lakatta, E. G. (2004). Rat Aortic MCP-1 and its Receptor CCR2 Increase with Age and Alter Vascular Smooth Muscle Cell Function. Atvb 24, 1397-1402. doi:10.1161/01. atv.0000134529.65173.08

Stefanadis, C., Vlachopoulos, C., Karayannacos, P., Boudoulas, H., Stratos, C., Filippides, T., et al. (1995). Effect of Vasa Vasorum Flow on Structure and Function of the Aorta in Experimental Animals. Circulation 91, 2669-2678. doi:10.1161/01.cir.91.10.2669

Stenmark, K. R., Yeager, M. E., El Kasmi, K. C., Nozik-Grayck, E., Gerasimovskaya, E. V., Li, M., et al. (2013). The Adventitia: Essential Regulator of Vascular wall Structure and Function. Annu. Rev. Physiol. 75, 23-47. doi:10.1146/annurevphysiol-030212-183802

Steppan, J., Wang, H., Bergman, Y., Rauer, M. J., Tan, S., Jandu, S., et al. (2019). Lysyl Oxidase-like 2 Depletion Is Protective in Age-Associated Vascular Stiffening. Am. J. Physiology-Heart Circulatory Physiol. 317, H49-H59. doi:10.1152/ajpheart.00670.2018

Sun, Z. (2015). Aging, Arterial Stiffness, and Hypertension. Hypertension 65, 252-256. doi:10.1161/hypertensionaha.114.03617 
Taghizadeh, H., Tafazzoli-Shadpour, M., Shadmehr, M., and Fatouraee, N. (2015). Evaluation of Biaxial Mechanical Properties of Aortic Media Based on the Lamellar Microstructure. Materials 8, 302-316. doi:10.3390/ma8010302

Theocharis, A. D., Manou, D., and Karamanos, N. K. (2019). The Extracellular Matrix as a Multitasking Player in Disease. FEBS J. 286, 2830-2869. doi:10. $1111 /$ febs. 14818

Theocharis, A. D., Skandalis, S. S., Gialeli, C., and Karamanos, N. K. (2016). Extracellular Matrix Structure. Adv. Drug Deliv. Rev. 97, 4-27. doi:10.1016/j. addr.2015.11.001

Thompson, R. W., Geraghty, P. J., and Lee, J. K. (2002). Abdominal Aortic Aneurysms: Basic Mechanisms and Clinical Implications. Curr. Probl. Surg. 39, 110-230. doi:10.1067/msg.2002.121421

Thorin-Trescases, N., and Thorin, E. (2016). Lifelong Cyclic Mechanical Strain Promotes Large Elastic Artery Stiffening: Increased Pulse Pressure and Old Age-Related Organ Failure. Can. J. Cardiol. 32, 624-633. doi:10.1016/j.cjca. 2015.12.022

Tinajero, M. G., and Gotlieb, A. I. (2020). Recent Developments in Vascular Adventitial Pathobiology. Am. J. Pathol. 190, 520-534. doi:10.1016/j.ajpath. 2019.10.021

Toda, T., Tsuda, N., Nishimori, I., Leszczynski, D. E., and Rummerow, F. A. (1980). Morphometrical Analysis of the Aging Process in Human Arteries and Aorta. Acta Anatomica 106, 35-44. doi:10.1159/000145167

Tronc, F., Mallat, Z., Lehoux, S., Wassef, M., Esposito, B., and Tedgui, A. (2000). Role of Matrix Metalloproteinases in Blood Flow-Induced Arterial Enlargement: Interaction with NO. Arterioscler Thromb. Vasc. Biol. 20, E120-E126. doi:10.1161/01.atv.20.12.e120

Trott, D. W., Henson, G. D., Ho, M. H. T., Allison, S. A., Lesniewski, L. A., and Donato, A. J. (2018). Age-related Arterial Immune Cell Infiltration in Mice Is Attenuated by Caloric Restriction or Voluntary Exercise. Exp. Gerontol. 109, 99-107. doi:10.1016/j.exger.2016.12.016

Tsamis, A., Krawiec, J. T., and Vorp, D. A. (2013). Elastin and Collagen Fibre Microstructure of the Human Aorta in Ageing and Disease: a Review. J. R. Soc. Interf. 10, 20121004. doi:10.1098/rsif.2012.1004

Ungvari, Z., Kaley, G., De Cabo, R., Sonntag, W. E., and Csiszar, A. (2010). Mechanisms of Vascular Aging: New Perspectives. Journals Gerontol. Ser. A: Biol. Sci. Med. Sci. 65A, 1028-1041. doi:10.1093/gerona/glq113

Ungvari, Z., Labinskyy, N., Gupte, S., Chander, P. N., Edwards, J. G., and Csiszar, A. (2008). Dysregulation of Mitochondrial Biogenesis in Vascular Endothelial and Smooth Muscle Cells of Aged Rats. Am. J. Physiology-Heart Circulatory Physiol. 294, H2121-H2128. doi:10.1152/ajpheart.00012.2008

Upala, S., Wirunsawanya, K., Jaruvongvanich, V., and Sanguankeo, A. (2017). Effects of Statin Therapy on Arterial Stiffness: A Systematic Review and MetaAnalysis of Randomized Controlled Trial. Int. J. Cardiol. 227, 338-341. doi:10. 1016/j.ijcard.2016.11.073

Upchurch, G. R., Jr., Ford, J. W., Weiss, S. J., Knipp, B. S., Peterson, D. A., Thompson, R. W., et al. (2001). Nitric Oxide Inhibition Increases Matrix Metalloproteinase-9 Expression by Rat Aortic Smooth Muscle Cells In Vitro. J. Vasc. Surg. 34, 76-83. doi:10.1067/mva.2001.115598

Urbano, R. L., Swaminathan, S., and Clyne, A. M. (2019). Stiff Substrates Enhance Endothelial Oxidative Stress in Response to Protein Kinase C Activation. Appl. Bionics Biomech. 2019, 6578492. doi:10.1155/2019/6578492

Vaitkevicius, P. V., Fleg, J. L., Engel, J. H., O'connor, F. C., Wright, J. G., Lakatta, L. E., et al. (1993). Effects of Age and Aerobic Capacity on Arterial Stiffness in Healthy Adults. Circulation 88, 1456-1462. doi:10. 1161/01.cir.88.4.1456

Wagenseil, J. E., and Mecham, R. P. (2009). Vascular Extracellular Matrix and Arterial Mechanics. Physiol. Rev. 89, 957-989. doi:10.1152/physrev. 00041.2008

Wallace, S. M. L., YasminMceniery, C. M., McEniery, C. M., Maki-Petäjä, K. M., Booth, A. D., Cockcroft, J. R., et al. (2007). Isolated Systolic Hypertension Is Characterized by Increased Aortic Stiffness and Endothelial Dysfunction. Hypertension 50, 228-233. doi:10.1161/hypertensionaha.107.089391
Wang, M., Fu, Z., Wu, J., Zhang, J., Jiang, L., Khazan, B., et al. (2012). MFG-E8 Activates Proliferation of Vascular Smooth Muscle Cells via Integrin Signaling. Aging Cell 11, 500-508. doi:10.1111/j.1474-9726.2012.00813.x

Wang, M., Jiang, L., Monticone, R. E., and Lakatta, E. G. (2014a). Proinflammation: the Key to Arterial Aging. Trends Endocrinol. Metab. 25, 72-79. doi:10.1016/j. tem.2013.10.002

Wang, M., Monticone, R. E., and Lakatta, E. G. (2014b). Proinflammation of Aging central Arteries: a Mini-Review. Gerontology 60, 519-529. doi:10.1159/ 000362548

Wang, M., Zhang, J., Jiang, L.-Q., Spinetti, G., Pintus, G., Monticone, R., et al. (2007). Proinflammatory Profile within the Grossly normal Aged Human Aortic wall. Hypertension 50, 219-227. doi:10.1161/hypertensionaha.107. 089409

Wang, M., Zhao, D., Spinetti, G., Zhang, J., Jiang, L.-Q., Pintus, G., et al. (2006). Matrix Metalloproteinase 2 Activation of Transforming Growth Factor-B1 (TGF-B1) and TGF- $\beta 1$-type II Receptor Signaling within the Aged Arterial Wall. Atvb 26, 1503-1509. doi:10.1161/01.atv.0000225777.58488.f2

Wang, R., Yu, X., and Zhang, Y. (2021). Mechanical and Structural Contributions of Elastin and Collagen Fibers to Interlamellar Bonding in the Arterial wall. Biomech. Model. Mechanobiol 20, 93-106. doi:10.1007/s10237-020-01370-z

Westerhof, N., Lankhaar, J.-W., and Westerhof, B. E. (2009). The Arterial Windkessel. Med. Biol. Eng. Comput. 47, 131-141. doi:10.1007/s11517-0080359-2

Woods, J. A., Wilund, K. R., Martin, S. A., and Kistler, B. M. (2012). Exercise, Inflammation and Aging. Aging Dis. 3, 130-140.

Yang, R., Fu, S., Zhao, L., Zhen, B., Ye, L., Niu, X., et al. (2017). Quantitation of Circulating GDF-11 and $\beta 2-M G$ in Aged Patients with Age-Related Impairment in Cognitive Function. Clin. Sci. (Lond) 131, 1895-1904. doi:10. $1042 / \operatorname{cs} 20171028$

Yeo, K. P., Lim, H. Y., and Angeli, V. (2021). Leukocyte Trafficking via Lymphatic Vessels in Atherosclerosis. Cells 10, 1344. doi:10.3390/cells10061344

Yin, H., and Pickering, J. G. (2016). Cellular Senescence and Vascular Disease: Novel Routes to Better Understanding and Therapy. Can. J. Cardiol. 32, 612-623. doi:10.1016/j.cjca.2016.02.051

Yurchenco, P. D. (2011). Basement Membranes: Cell Scaffoldings and Signaling Platforms. Cold Spring Harb Perspect. Biol. 3, a004911. doi:10.1101/cshperspect. a004911

Zaragoza, C., Balbín, M., López-Otín, C., and Lamas, S. (2002). Nitric Oxide Regulates Matrix Metalloprotease-13 Expression and Activity in Endothelium. Kidney Int. 61, 804-808. doi:10.1046/j.1523-1755.2002.00224.x

Zhu, Y., Qiu, H., Trzeciakowski, J. P., Sun, Z., Li, Z., Hong, Z., et al. (2012). Temporal Analysis of Vascular Smooth Muscle Cell Elasticity and Adhesion Reveals Oscillation Waveforms that Differ with Aging. Aging Cell 11, 741-750. doi:10.1111/j.1474-9726.2012.00840.x

Conflict of Interest: The authors declare that the research was conducted in the absence of any commercial or financial relationships that could be construed as a potential conflict of interest.

Publisher's Note: All claims expressed in this article are solely those of the authors and do not necessarily represent those of their affiliated organizations, or those of the publisher, the editors and the reviewers. Any product that may be evaluated in this article, or claim that may be made by its manufacturer, is not guaranteed or endorsed by the publisher.

Copyright $\odot 2022$ Mammoto, Matus and Mammoto. This is an open-access article distributed under the terms of the Creative Commons Attribution License (CC BY). The use, distribution or reproduction in other forums is permitted, provided the original author(s) and the copyright owner(s) are credited and that the original publication in this journal is cited, in accordance with accepted academic practice. No use, distribution or reproduction is permitted which does not comply with these terms. 